\title{
WAR BULLETIN: AN APPEAL TO THE MEDICAL PROFESSION
}

Lieutenant Col. R. E. Noble, M. C., U. S. A., chief of the Personnel Desk of the Surgeon General's Office, presented before the last meeting of the Southern Medical Association, a most admirable paper, which convincingly answers the many questions asked of the Department, and which have caused perplexing hours of thought with many doctors.

In a previous paper by the same writer, presented prior to the time that the United States entered the world struggle, as in the above referred to communication, Col. Noble said: "On the medical profession rests a heavy responsibility, for with the medical profession rests the subject of medical preparedness."

The largely increased army now in course of mobilization naturally will require a greater number of Officers in the Medical Reserve Corps.

At the present time, according to a statement made by Lieut. Col. Noble, we have only 14,500 doctors in the Medical Reserve Corps, not a sufficient number to care for those already in the service, not mentioning the men to come into combatant forces as the result of a second draft.

With the new draft soon to be called and the possibility of the raising of an army of between five and ten million, as has been authoritatively foreshadowed, we would repeat "On the medical profession rests a heavy responsibility, for with the medical profession rests the subject of medical preparedness."

The responsibility of the medical profession of the United States and its importance in the successful outcome of the war cannot be too forcibly impressed upon every doctor who is mentally and physically fit and within the age limit, and they are urged to offer their services now.

That the Surgeon General should have an immense Corps of Medical Reserve Officers upon which to draw, enabling him to place the individual where he will be best fitted for the service, is manifestly apparent. This will mean efficiency and by efficiency alone can the responsibility now resting upon the medical profession of this county be lessened.

Will you not apply at once for a commission in the Medical Reserve Corps and thus relieve the responsibility which you owe to your country, your profession and yourself? 